European

Neurology
Eur Neurol 2006;56:31-36

DOI: $10.1159 / 000095138$
Received: June 15, 2006

Accepted: June 16, 2006

Published online: August 17, 2006

\title{
The Enigma of Chronic Fatigue
}

\author{
J.M.S. Pearce \\ Emeritus Consultant Neurologist, Hull Royal Infirmary and Hull York Medical School, Hull, UK
}

\section{Key Words}

Chronic fatigue $\cdot$ Fatigue assessment $\cdot$ Neurasthenia

\begin{abstract}
Until new, reproducible criteria are established, the ubiquitous 'chronic fatigue state' emerges as a non-specific complaint shared by many different entities. Presently, it is neither a valid nor a verifiable medical diagnosis.
\end{abstract}

Copyright $\odot 2006$ S. Karger AG, Base

\section{Introduction}

The Oxford English Dictionary defines fatigue as lassitude or weariness resulting from either bodily or mental exertion; or physiologically as a condition of muscles, organs, or cells characterized by a temporary reduction in power or sensitivity following a period of prolonged activity or stimulation. This paper questions its employment as a valid medical diagnosis.

\section{History}

A 1966 Lancet editorial recounted that in the 16th century, 'Fatigue' first appeared as a description of tedious duty [1]. In the early 19th century, 'the delicate and easily exhausted upper class was succeeded by the hardworking lower classes, who laboured under a Protestant work ethic. The accompanying lifestyle of the industrial revolution machinery induced noise, excitement and a fear of accidents' [1]. In 1857, the French physician E.A. Duschene (cited by Barnett [2]) identified the 'maladie des mecaniciens'. Victorian doctors regarded the soul as something that could be exhausted by overuse or over-stimulation of body or mind. Fatigue was not just physical, but also mental [3]. 'Neurasthenia' was a descriptive term coined by George Miller Beard [4] for what was colloquially known as 'nervous exhaustion' - commonplace in the 19th century; the word has the merits of simplicity and its meaning is self-evident. A celebrated example was the philosopher and psychologist Herbert Spencer. In his later years, dogged by fatigue and depression, 'The retreat into illness was also for Spencer a retreat from social intercourse' [5].

The concept of neurasthenia declined between the 1930s and 1960s. But curiously, in the 1980s, when the term 'chronic fatigue' emerged as a medical term, neurasthenia was not replaced but reappeared. The symptoms of fatigue were modern variants of neurasthenia, which had 'adopted the organic inheritance of Beard's ideas of neurasthenia, despite the fact that the question of organicity could not be decisively answered in a single case' [6].

In both World Wars, combat fatigue was a nervous disorder resulting from prolonged or severe battle experience. In modern times, fatigue worryingly appears to be burgeoning in the healthy population, and cultural trends uncover the symptom as a common complaint that on enquiry often closely relates to a state of boredom, especially in teenagers. Yet, the intensity of complaints is no less severe in teenage boredom than in illness: 'Fatigue is more than tiredness - pathological exhaustion, perhaps - and in its medical sense it has been associated with modernity, with fear of the new' [2].

\section{KARGER}

Fax +41613061234

E-Mail karger@karger.ch

www.karger.com (c) 2006 S. Karger AG, Basel

0014-3022/06/0561-0031\$23.50/0

Accessible online at:

www.karger.com/ene
J.M.S. Pearce

304 Beverley Road, Anlaby, East Yorks, HU10 7BG (UK) 


\section{Clinical Setting}

Analysis of tiredness or fatigue is a vexing problem. In contrast to blood glucose or pulse rate, fatigue is immeasurable. Management is hampered by the uncertainty of its cause and the lack of specific treatment. The complaint of tiredness or fatigue is recorded in almost all medical illnesses, ranging from acute and chronic infections to heart, kidney and respiratory failure, and every variety of cancer, neoplastic diseases and their treatments. Degenerative diseases of the nervous system are similarly often complicated by fatigue. Although common in advanced disease when physical disability, pain, sleeplessness, loss of morale and reactive depression are frequent [e.g. in arthritis, multiple sclerosis (MS), Parkinsonism, stroke, ankylosing spondylitis, systemic lupus erythematosus], it can occur in non-disabled patients in the early stages of illness. Fatigue, both physical and mental, is also prominent in a variety of anxiety and depressive illnesses and has attracted the dubious term 'mild astheno-emotional disorder' [7] to characterize it. Fatigue can diminish both the quality of life and physical function.

Because its significance in the individual is difficult to assess, it is essential to ascertain a baseline, i.e. the prevalence of the symptom in the healthy population.

\section{‘Normal Population'}

In a cross-sectional questionnaire study in the Danish general population (a random, age-stratified sample of 1,608 people aged $20-77$ years), five fatigue scales were appraised [8]. Fatigue was classed as: General, Physical, Reduced activity, Reduced motivation, or Mental, with overall positive scores for $18-35 \%$ of the population. Severe tiredness was more common in females though gender differences were generally small. General and Mental fatigue decreased linearly with age. Depressed respondents scored substantially higher on all scales, especially on Mental fatigue. Respondents with low social status and depression had high fatigue scores on all scales, independent of other factors. The effect of somatic disease depended on age, gender and/or whether the person was living alone. Physical and mental diseases play essential parts for the level of fatigue and as modulators of the associations between sociodemographic factors and fatigue.

Another recent study, by Furberg et al. [9], concludes: 'Prevalence for different definitions of self-reported lifetime fatigue ranged from $36.7 \%$ for any fatigue to $2.7 \%$ for chronic fatigue syndrome-like illness. Females were two to three times more likely to report fatigue than males ... People with lifetime fatigue had more compromised functional status than people without lifetime fatigue. Self-reported lifetime fatiguing illness varied widely depending upon the definitions adopted.'

\section{Difficulties in Assessing Fatigue}

We must therefore start by accepting that tiredness or a sense of fatigue are commonplace normal experiences [10]. As Giovanni [10] reasonably says, 'It is a subjective feeling of tiredness or exhaustion which could refer to both physical (motor activities) and mental (cognitive or emotional) processes'.

The complex sensations may result from the physiological fatigue of temporary lack of sleep, strenuous exertion, or the converse state of physical inertia and mental boredom. But the reliability and applicability of epidemiological data to the individual is questionable. Definition remains controversial, arbitrary, but important.

Fatigue and fatigability are in themselves not pathological. 'Fatigue' simply refers to being tired or unable to maintain expected force. 'Fatigability' is a measure of how easily someone feels tired. Fatigue may describe many experiences, from the exhaustion of a marathon to the sleepiness following prolonged wakefulness. Crucially, the complaints of mental and physical fatigue often fail to correlate with cognitive function or physical muscle fatigue. For example, patients with chronic fatigue syndrome (CFS) describe feelings of muscle weariness or tiredness unrelated to objective measures of muscle fatigue [11]. In a separate study, DeLuca et al. [12] found that the CFS group did not differ from the control subjects on tasks of cognitive functioning (e.g., memory), even though they showed a high degree of subjective complaint of cognitive impairment.

Some authorities assert that, "true fatigue and ... tiredness are plainly different', or 'fatigue is more than tiredness' and refer to 'pathological exhaustion' [2]. The accuracy of these assertions is doubtful. The stoical denials of tiredness or its too easy assertion, determine how patients, questionnaire respondents and physicians use the words. Does 'exhaustion', as cited above imply that an athlete's transient, physiological exhaustion is abnormal? Some argue that fatigue is only pathological if it is disabling - that is, if it affects a person's social, physical and occupational wellbeing. But that criterion, too, incorpo- 
Table 1. Centers for Disease Control and Prevention's diagnostic criteria for $\mathrm{CFS}^{1}$

Major criteria (both required)

- Debilitating fatigue reducing activity to less than $50 \%$ of the patient's premorbid activity for at least 6 months (in adolescents usually reduced to 3 months)

- Symptoms not explained by other medical or chronic psychiatric illness. The presence of non-psychotic depression does not preclude the diagnosis of CFS

Symptom criteria (four required)

- Sore throat

- Painful cervical or axillary lymphadenopathy

- Muscle discomfort or pain

- Prolonged generalized fatigue after usual levels of activity

- Headaches

- Arthralgias (without swelling or redness)

- Neuropsychological disorders, e.g. forgetfulness \& lack of concentration

- Sleep disturbance (unrefreshing sleep)

${ }^{1}$ Adapted from Fukuda et al. [13].

rates a large subjective element in which the sufferer defines his/her own threshold for distinguishing when it is or is not disabling. For want of a satisfactory definition, the Centres for Disease Control and Prevention (CDC) defined 'profound fatigue', which they imply is 'pathological fatigue'; in the context of CFS as, '... [fatigue] not improved by bed rest and that may be worsened by physical or mental activity' [13].

There has been criticism of these criteria. For example, Dale and Straus [14] pointed out that some psychiatric illnesses could be secondary to prolonged fatigue and that the CDC criteria did not clearly define when psychiatric illness is an exclusion criteria or when it is a defining criterion. Only the group with a chronic psychiatric illness that preceded the development of chronic fatigue was excluded (table 1). The UK (Oxford) criteria [15] have also not escaped criticism.

\section{Fatigue in Neurological Disease}

Two different symptom phenomena should be distinguished. One is muscle tiredness succeeding exertion ('peripheral fatigue'); the other is a more general loss of energy, disinclination to move often described as weariness, lassitude, or anergia (labelled 'central fatigue'). Appraisal of neurological (i.e. central) diseases might in theory point to a mechanism of central fatigue. About 50-
$80 \%$ of subjects with MS have fatigue and in half of them it is their most disabling symptom. However, Krupp et al. [16] showed that fatigue was largely independent of selfreported depressive symptoms in MS. But the increased attention given to MS patients with fatigue during investigations has been noted to improve the symptom, suggesting psychosomatic factors. Similarly, in treatment studies of MS, Krupp et al. [17] and the Canadian MS Research Group [18] noticed a decline in fatigue severity for all patients between their first and second study visits, 'even before starting treatment'.

MS patients, who have normal baseline strength on testing, develop greater 'physiological' fatigue during maximal sustained contraction (adductor pollicis), which is considered central in origin. However, there is no correlation between the amount of inducible fatigue and that of fatigue experienced in everyday life, suggesting that other factors contribute to this symptom. Despite subjective central fatigue, there is no central motor dysfunction as tested by transcranial magnetic stimulation, and no firm evidence of frequency-dependent conduction block, which might generate physiological fatigue [19]. The absence of a demonstrable increase in motor pathway dysfunction, Sheean et al. [19] speculate, may be due to impaired drive to the primary motor cortex - not due to a lack of motivation.

Physical fatigue often occurs in diverse conditions such as Parkinsonism [20], post-polio syndrome, and in immune-mediated polyneuropathy, where fatigue has been related to anxiety, depression, functional disability and poor quality of life [21]. In Guillain-Barré syndrome, it is rarely disabling [22], though endurance intolerance may persist for years. Investigation of fatigue in these disorders has not yielded a consistent, definable central mechanism.

\section{Chronic Fatigue Syndrome}

In chronic fatigue syndrome (CFS), fatigue dominates the many disabling symptoms variably present. But if ' $f a-$ tigue is only pathological if it is disabling ...' [12], it is 'pathological' in all sufferers from CFS, including an important subgroup whose complaints recover within a year. The syndrome, clinically defined, is characterized by severe disabling fatigue and prominently features subjective impairments in concentration, short-term memory and sleep as well as musculoskeletal pain. Eighteen percent of patients in the Centers for Disease Control and Prevention (CDCP) Report [13] were found to have a pre- 
existing medical condition that plausibly accounted for their chronic fatiguing illness. Diagnosis is by exclusion, since no pathognomonic signs or diagnostic tests have been validated in scientific studies; moreover, no consistently effective treatments exist. There is no convincing evidence to demonstrate persisting viral infection as a general cause. Patients show a high incidence $(\sim 60 \%)$ of depression, emotional symptoms and low self-esteem, although many assert that CFS is not merely a masked form of depression or a somatoform disorder. Acute post-viral fatigue syndromes are common in adolescence, but it is unclear why they become chronic in some young people [11]. Longitudinal studies show that some persons affected by CFS improve, but many remain functionally impaired for several years.

Fatigue is usually accompanied by other symptoms, many characteristically psychogenic (table 1) [23]. Wessely and Powell [24] prospectively studied 47 patients with unexplained chronic post-viral fatigue (CFS) and compared them with control patients with neuromuscular and affective disorders. Using criteria that excluded fatigue itself as a symptom, $72 \%$ of the CFS patients were classed as 'psychiatric disorder' compared with $36 \%$ of the neuromuscular group. Mental fatigue and fatigability was equally common in CFS and depressed patients, but only occurred in those neuromuscular patients who were also classed as psychiatric disorder: 'Overall, the CFS patients more closely resembled the depressed than the neuromuscular patients.'

\section{Medicalized Labels}

Doctors sometimes reject fatigue as a symptom of neurosis, for fear of implying it is not genuine. This arises mainly in the absence of a robust, verifiable definition and because assessment is subjective. Fatigue can easily be exaggerated by patients but also by caring professionals, whose zealous attentions iatrogenically can induce or worsen the symptoms [25]. Epidemics and ill-founded melodramatic nomenclature (e.g., ME) aggravate the confusion.

Understanding the symptom and hence its place in an acceptable medical taxonomy is hindered by inconsistency of definition, methodology and the characteristics of patients [26]:

- the use by researchers of heterogeneous study groups,

- the use of study groups selected using different definitions of CFS, and
- the invalid comparisons of contradictory research findings stemming from the above.

Proponents of uncritical diagnostic labels [27], not content with their all-embracing 'diagnostic' criteria, add a lengthy footnote of no less than 14 'co-morbid entities: fibromyalgia syndrome, myofascial pain syndrome, temporomandibular joint syndrome, irritable bowel syndrome, interstitial cystitis, irritable bladder syndrome, Raynaud's phenomenon, ....'

To make sure nobody with fatigue is denied a medicalized label, they continue: 'If the patient has unexplained prolonged fatigue (6 months or more) but has insufficient symptoms to meet the criteria for ME/CFS, it should be classified as idiopathic chronic fatigue.'

Fowler et al.'s [28] paediatric study similarly concludes: 'Children and adolescents who do not fulfil the current narrow definition of CFS but do suffer from disabling fatigue show comparable and substantial impairment. In primary care settings, a broader definition of disabling fatigue [sic] would improve the identification of impaired children and adolescents who require support.'

\section{Physiology; Peripheral Fatigue}

'Can chronic fatigue be explained physiologically?', is a pertinent question in the absence of a demonstrable pathogenesis.

Measuring anxiety-related physiological and psychological reactions to ordinary activity and exercise, CFS patients and healthy sedentary controls were assessed before, during and after an incremental exercise test on a motorized treadmill [29]. Patients with CFS were more fatigued and sleep disturbed than were the controls and they noted greater effort during the exercise test. No statistically significant differences were found in either heart rate or galvanic skin resistance during a normal day and before, during and after the exercise test.

Muscle tiredness ('peripheral fatigue') is distinguished arbitrarily from the more general weariness, lassitude, or anergia ('central fatigue': see above). Muscle fatigue is frequently defined as a temporary loss in forceor torque-generating ability because of recent, repetitive muscle contraction. The development results from the failure of several processes, including motor (muscle) unit recruitment and firing rate, chemical transmission across the neuromuscular junction, propagation of the action potential along the muscle membrane and tubules, calcium ion $\left(\mathrm{Ca}^{2+}\right)$ release from the sarcoplasmic 
reticulum, $\mathrm{Ca}^{2+}$ binding to troponin $\mathrm{C}$, and cross-bridge cycling.

Interestingly, there is insufficient evidence to suggest that this type of fatigue determines functional limitations and disability [30].

Recovery of power after exercise can be very slow, in some instances requiring days to be completed. This prolonged fatigue-induced weakness is called delayed lowfrequency recovery. However, symptoms of fatigue in CFS patients last much longer than several days. Thus physiological investigations have so far failed to account for a peripheral cause of chronic fatigue. By exclusion, the concept of central fatigue is widely held to explain chronic fatigue states.

\section{Central Fatigue: Aetiological Considerations}

We have shown that diseases of the central nervous system fail to provide a general or specific mechanism for concepts of central fatigue. The factors associated in the literature with CFS might lend understanding to this phenomenon. They include: genetic factors, brain abnormalities (an underactive hypothalamo-pituitary-adrenal axis), deficiencies in cortisol levels or high levels of serotonin, trace element deficiencies, a hyper-reactive immune system, many viral or other infectious agents (such as Epstein-Barr virus), psychiatric or emotional disorders. But the main evidence for such associations has come from retrospective case-control studies, which are subject to many inconsistencies and ascertainment bias [31].

Most investigations show associations, but no specific causal agent(s) that account for patients' symptoms. Equally, although graded exercises and cognitive behavioural treatments help some sufferers, no generally adequate or curative therapy exists [32].

It is fascinating that with the massive psychological 'shell shock' of the First World War traumata, 'railway fatigue' disappeared: an interesting hint that biosocial preoccupations can determine the expression of human symptoms. In the aftermath of the 'September 11' terrorist attack, the incidence of fatigue syndromes strikingly diminished: prolonged fatigue: 5,450 vs. $1,530 / 100,000$, $\mathrm{p}=0.010$; CFS-like illness: 2,510 vs. $960 / 100,000, \mathrm{p}=$ 0.014 [33]. The causes of this effect are unknown but suggest that perception or manifestation of fatigue can be modified by acute psychological and physiological diversion and adaptations.

\section{Conclusion}

In a vast literature, most consider chronic fatigue as a non-specific result of diverse aetiologies. However, there is much inconsistency of definition, methodology and the characteristics of patients between different publications. Little attempt has been made to dissect cause from association or effect(s) in the positive laboratory findings. Many uncertainties have fuelled controversy, polarizing opinions. Patients who meet CFS definitions do not substantially differ by demographic characteristics, symptoms and other illness features from those who fail to satisfy the definition (CDCP). The 1996 Oxford Textbook of Medicine summarized the dilemma: 'The nature, pathology, and aetiology of this syndrome remain controversial, so the purely descriptive term chronic fatigue syndrome is generally preferred.'

The CDCP report [13] asserts: 'The central issue in chronic fatigue syndrome research is whether the chronic fatigue syndrome or any subset of it is a pathologically discrete entity, as opposed to a debilitating but nonspecific condition shared by many different entities.'

Few would disagree. We are left with a complaint (symptom), sometimes debilitating, whose basis lies in constitutional factors, the clinical onset precipitated by physical or psychogenic illness or by no identifiable precedent, the course determined by individual resilience and by the social and family reactions to the symptoms. By constitutional is implied the inherent resilience to stresses both organic and emotional; and the ability to succumb to, or withstand such stresses, with consequently restricted or unrestricted work, social function and quality of life.

If adopted without adequate cause, the lifestyle of a chronic fatigue invalid is a grave misfortune for the patient, but also for its reflection on current social attitudes prone to encourage such states. It is not surprising that profound scepticism of this type of illness prevails in certain observers, as the following quotation from Nemesis (Ivan Illich, 1976) illustrates: [On Western Medicine as a mechanism for social control] 'It serves to legitimise social arrangements into which many people do not fit. It labels the handicapped as unfit, and breeds ever new categories of patients. People who are angered, sickened and impaired by their industrial labour and leisure can escape only into a life under medical supervision and are thereby seduced or disqualified from political struggle for a healthier world.'

The portentous diagnostic labels given to these patients foster rather than alleviate illness. It is possible that 
biological factors deriving from a primary illness or incident initiate the process. Whereas most recover without sequelae, in certain subjects the symptoms and disabilities persist and are often discrepant with the initial illness or injury. In this group, the patients' behaviour may reflect a desire to attain the sick role for secondary gain. If society eliminated the stigma of psychological illness, and opposed exaggeration and simulation of illness, then such chronic disability with 'retreat into illness' might disappear [34]. To what extent some patients retreat into a fatigue illness by virtue of intolerable social stresses remains uncertain. The overzealous prescription of diagnoses, medically enforced rest and inactivity, continue to perpetuate symptoms and hinder recovery. Until new, reproducible criteria emerge, we have to agree with the CDCP report that chronic fatigue is a debilitating but non-specific condition shared by many different entities. However, it is neither a valid medical diagnosis nor a verifiable one.

\section{References}

1 Anonymous. Fatigue. Lancet 1966;i:585586.

2 Barnett R: Fatigue. The Lancet 2005;366:1.

3 Beaulieu JK: The Issues of Fatigue and Working Time in the Road Transport Sector. International Labour Office, Geneva, 2005, p. 9. http:/www.ilo.org/public/english/dialogue/sector/papers/transport/wp232.pdf.

4 Beard G: Neurasthenia, or nervous exhaustion. Boston Med Surg J 1869;3:217-221.

5 Coser LA: Masters of Sociological Thought: Ideas in Historical and Social Context, ed 2. New York, Harcourt Brace, 1977.

6 Schafer ML: Zur Geschichte des Neurastheniekonzeptes und seiner modernen Varianten Chronic-Fatigue-Syndrom, Fibromyalgie sowie Multiple Chemische Sensitivität. Fortschr Neurol Psychiatr 2002;70:570582.

7 Lindqvist G, Malmgren H: Organic mental disorders as hypothetical pathogenetic processes. Acta Psychiatr Scand Suppl 1993;373: 5-17.

-8 Watt T, Groenvold M, Bjorner JB, Noerholm V, Rasmussen NA, Bech P: Fatigue in the Danish general population. Influence of sociodemographic factors and disease. J Epidemiol Community Health 2000;54:827-833.

-9 Furberg H, Olarte M, Afari N, Goldberg J, Buchwald D, Sullivan PF: The prevalence of self-reported chronic fatigue in a U.S. twin registry. J Psychosom Res 2005;59:283-290.

10 Giovannoni G: Multiple sclerosis-related fatigue. J Neurol Neurosurg Psychiatry 2006; $77: 2-3$.

11 Wessely S: The neuropsychiatry of chronic fatigue syndrome. Ciba Found Symp 1993; 173:212-229.

-12 DeLuca J, Johnson SK, Beldowicz D, Natelson BH: Neuropsychological impairments in chronic fatigue syndrome, multiple sclerosis, and depression. J Neurol Neurosurg Psychiatry 1995;58:38-43.
13 Fukuda K, Straus SE, Hickie I, Sharpe MC Dobbins JG, Komaroff A: The chronic fatigue syndrome: a comprehensive approach to its definition and study. International Chronic Fatigue Syndrome Study Group. Ann Intern Med 1994;121:953-959.

14 Dale JK, Straus SE: The chronic fatigue syndrome: considerations relevant to children and adolescents. Adv Pediatr Infect Dis 1992; 7:63-83.

15 Sharpe M, Archard L, Banatvala J, et al: Chronic fatigue syndrome: guidelines for research. J R Soc Med 1991;84:118-121.

16 Krupp LB, LaRocca NG, Muir-Nash J, et al: The fatigue severity scale. Application to patients with multiple sclerosis and systemic lupus erythematosus. Arch Neurol 1989;46: 1121-1123.

17 Krupp LB, Coyle PK, Doscher C, Miller A Cross AH, Jandorf L, Halper J, Johnson B, Morgante L, Grimson R: Fatigue therapy in multiple sclerosis: results of a double-blind, randomized, parallel trial of amantadine, pemoline, and placebo. Neurology 1995;45: 1956-1961.

18 The Canadian MS Research Group: A randomized controlled trial of amantadine in fatigue associated with multiple sclerosis. Can J Neurol Sci 1987;14:273-278.

19 Sheean GL, Murray NM, Rothwell JC, Miller DH, Thompson AJ: An electrophysiological study of the mechanism of fatigue in multiple sclerosis. Brain 1997;120:299-315.

20 Pearce JMS: Parkinson's Disease and Its Management. Oxford, Oxford University Press, 1992.

21 Garssen MPJ, Schmitz PIM, Merkies ISJ, Jacobs BC, van der Meché FGA, van Doorn PA: Amantadine for treatment of fatigue in Guillain-Barré syndrome: a randomised, double blind, placebo controlled, crossover trial. J Neurol Neurosurg Psychiatry 2006;77:61-65.

22 Ropper AH, Wijdicks EFM, Truax BT, et al: Guillain-Barré syndrome. Philadelphia, FA Davis Co, 1991

23 Wessely S, Hotopf M, Sharpe M: Chronic Fatigue and Its Syndromes. Oxford University Press, Oxford, 1998.
24 Wessely S, Powell R: Fatigue syndromes: a comparison of chronic 'postviral' fatigue with neuromuscular and affective disorders. J Neurol Neurosurg Psychiatry 1989;52:940948.

25 Pearce JMS: Chronic regional pain and chronic pain syndromes. Spinal Cord 2005; 43:63-68.

26 Report of the National Task Force on Chronic Fatigue Syndrome (CFS), Post-Viral Fatigue Syndrome (PVFS) and Myalgic Encephalomyelitis (ME). Westcare, Bristol, supported by UK Department of Health, 1994.

27 Carruthers BM, Jain AK, De Meirleir KL, Peterson DL, et al: Myalgic encephalomyelitis/ chronic fatigue syndrome: clinical working case definition, diagnostic and treatment protocols. J Chronic Fatigue Syndr 2003;11: 7-116.

28 Fowler T, Duthie P, Thapar A, Farmer A: The definition of disabling fatigue in children and adolescents. BMC Fam Pract 2005;6:33.

29 Gallagher AM, Coldrick AR, Hedge B, Weir WR, White PD: Is the chronic fatigue syndrome an exercise phobia? A case control study. J Psychosom Res 2005;58:367-373.

- 30 Stackhouse SK, Reisman DS, Binder-Macleod SA: Challenging the role of $\mathrm{pH}$ in skeletal muscle fatigue. Phys Ther 2001;81:18971903.

- 31 Wessely S, Chalder T, Hirsch S, Pawlikowska T, Wallace P, Wright DJ: Postinfectious fatigue: prospective cohort study in primary care. Lancet 1995;345:1333-1338.

- 32 Garssen MP, Bussmann JB, Schmitz PI, et al: Physical training and fatigue, fitness, and quality of life in Guillain-Barré syndrome and CIDP. Neurology 2004;63:2393-2395.

- 33 Heim C, Bierl C, Nisenbaum R, Wagner D, Reeves WC: Regional prevalence of fatiguing illnesses in the United States before and after the terrorist attacks of September 11, 2001. Psychosom Med 2004;66:672-678.

34 Pearce JMS: Psychosocial factors in chronic disability. Med Sci Monit 2002;8:275-281. 